УДК 615.322

\title{
ИЗУЧЕНИЕ НЕКОТОРЫХ ВОДОРАСТВОРИМЫХ СОЕДИНЕНИЙ ДОННИКА ЛЕКАРСТВЕННОГО ТРАВЫ (MELILOTUS OFFICINALIS L.)
}

\author{
() Л.М. Федосеева*, Т.А. Харлампович
}

Алтайский государственный медицинский университет, пр. Ленина, 40, Барнаул, 656038 (Россия), e-mail: ludmila@agmu.ru

\begin{abstract}
Физико-химическими методами исследован компонентный состав водорастворимых соединений донника лекарственного травы. Установлено количественное содержание полисахаридов, аминокислот, фенольных соединений в водном извлечении донника лекарственного травы.

Методом высокоэффективной жидкостной хроматографии (ВЭЖХ) установлен качественный и количественный состав моносахаридов и аминокислот. Дана общая характеристика полифенольных соединений.

Ключевые слова: донник лекарственный, водорастворимые полисахариды, уроновые кислоты, моносахариды, аминокислоты, дубильные вещества, галловая кислота.
\end{abstract}

\section{Введение}

Донник лекарственный - двухлетнее травянистое растение семейства бобовых (Fabaceae). В медицинских целях заготавливают верхушки побегов с листьями и цветами. Донника лекарственного трава обладает антиангинальным, антигипертензивным, антикоагулянтным, антиагрегантным, седативным действием. В народной медицине применяется при стенокардии, тромбозе коронарных сосудов, а также в качестве наружного раздражающего и отвлекающего средства $[1,2]$.

В траве донника лекарственного содержится кумарин, кумаровые кислоты, мелилотозид, гликозиды кверцетина и кемпферола, жироподобные вещества, полисахариды. Не допускается присутствие в растительном сырье токсичного вещества дикумарола, который образуется в результате неправильной заготовки [3-5].

Водорастворимые полисахариды донника лекарственного травы представляют особый интерес. Данные вещества, долгое время считавшиеся баластными, активно изучаются. Одно из направлений - профилактика и лечение сердечно-сосудистых заболеваний. Установлено, что полисахариды донника лекарственного стимулируют процессы кроветворения, обладают противовоспалительным и антиоксидантным действием, защищают клетки крови от неблагоприятных воздействий, активируют работу ферментных систем клеток крови и фагоцитоз [6, 7].

При разработке технологии получения сухого экстракта донника лекарственного травы водорастворимые полисахариды и аминокислоты могут рассматриваться как биологически активные соединения. В свою очередь, дубильные вещества, при высоком содержании в сырье, могут нивелировать действие некоторых соединений [8]. Для расширения сведений о химическом составе растительного сырья и разработки технологии получения экстракта необходимо изучение водорастворимых веществ донника лекарственного травы.

Федосеева Людмила Михайловна - заведующая кафедрой фармацевтической химии с курсом органической и токсикологической химии, доктор фармацетических наук, профессор, тел.: (3852) 24-02-78, e-mail: ludmila@ agmu.ru Харлампович Татьяна Анатольевна - аспирант, тел.: (3854) 39-01-95, e-mail: ludmila@agmu.ru

\section{Экспериментальная часть}

В качестве объектов исследований использовали образцы донника лекарственного травы, заготовленные на территории Бийского, Алтайского, Завьяловского, Красногорского районов Алтайского

\footnotetext{
* Автор, с которым следует вести переписку.
} 
края. Сырье собирали в период цветения, проводили естественную сушку и измельчали до размера частиц, проходящих сквозь сито с отверстиями диаметром 3 мм.

Для извлечения водорастворимых полисахаридов измельченное сырье предварительно обрабатывали смесью хлороформ - метанол (2 : 1), с целью удаления липофильных и фенольных соединений, затем экстрагировали водой в соотношении 1:10 на водяной бане с обратным холодильником в течение 30 мин. Извлечение декантировали, экстракцию повторяли еще дважды. К объединенному извлечению после центрифугирования прибавляли трехкратный объем этилового спирта 96\% и выдерживали в течение 1 ч при комнатной температуре для осаждения полисахаридов. Надосадочную жидкость декантировали, не допуская взмучивания образовавшегося осадка, фильтровали с помощью водоструйного вакуумного насоса через высушенный до постоянной массы стеклянный фильтр «ПОР 16». На этот же фильтр количественно переносили осадок полисахаридов, промывая последовательно этиловым спиртом 96\% и ацетоном. Фильтр с осадком высушивали на воздухе, затем при температуре $100-105{ }^{\circ} \mathrm{C}$ до постоянной массы [9].

Содержание уроновых кислот в выделенной фракции водорастворимых полисахаридов (ВРПС) определяли карбазольным методом. Оптическую плотность комплекса красного цвета измеряли на спектрофотометре «Cary 300» при длине волны 535 нм. В качестве стандартного образца использовали галактуроновую кислоту (Fluka) [10].

Для определения моносахаридного состава проводили гидролиз ВРПС в среде трифторуксусной кислоты 2М. Гидролизаты анализировали на хроматографическом модуле «Alliance», оснащенном рефрактометрическим детектором и хроматографической колонкой Sugar-Pak $(300 \times 7,8)$ мм в следующих условиях: подвижная фаза - вода для хроматографии; температура колонки - $90{ }^{\circ} \mathrm{C}$; температура ячейки детектора $40{ }^{\circ} \mathrm{C}$; скорость потока - 0,5 мл/мин; объем инжекции - 20 мкл.

Идентификацию и количественное определение моносахаридов проводили методом внешнего стандарта в сравнении с хроматограммами водных растворов фруктозы, глюкозы, галактозы, арабинозы, маннозы, ксилозы, рамнозы (Sigma).

Идентификацию свободных аминокислот в водном извлечении травы донника лекарственного проводили с помощью тонкослойной хроматографии и высокоэффективной жидкостной хроматографии. В качестве стандартных образцов использовали аминокислоты фирмы Sigma.

Тонкослойную хроматографию осуществляли на пластинах HPTLC Silica gel $60 \mathrm{~F}_{254}$ с алюминиевой подложкой (Merck) в системе растворителей: бутанол - ацетон - уксусная кислота - вода (14:14: $4: 8)$. В качестве детектирующего реагента использовали раствор нингидрина в этиловом спирте $96 \%$.

Содержание свободных аминокислот определяли методом ВЭЖХ на хроматографе «Alliance», оснащенном испарительным детектором светорассеяния и колонкой ProteCol-P C 18 HPH125 (250×4,6) мм, 5 мкм в следующих условиях: подвижная фаза - 0,1\% раствор гептафтормасляной кислоты в 0,2\% растворе трифторуксусной кислоты; температура колонки - $30{ }^{\circ} \mathrm{C}$; температура испарительной трубки - $50{ }^{\circ} \mathrm{C}$; давление газа (азот) - 45 рsi; объем пробы - 10 мкл; скорость потока - 0,5 мл/мин.

Общее содержание аминокислот определяли по нингидриновой реакции [11] с использованием в качестве стандартного образца аргинина фирмы Sigma. Оптическую плотность образующегося синефиолетового комплекса измеряли на спектрофотометре в максимуме поглощения при длине волны 568 нм.

Содержание суммы фенольных соединений и дубильных веществ в водном извлечении донника лекарственного травы определяли спектрофотометрическим методом с реактивом Фолина-Чокальтеу [12]. Для количественного определения дубильных веществ использовали их способность сорбироваться кожным порошком. В качестве стандартного образца использовали галловую кислоту (Sigma).

Групповую принадлежность полифенольных соединений определяли по качественным реакциям, основанным на образовании окрашенных комплексов при взаимодействии дубильных веществ с солями тяжелых металлов [13].

В водных извлечениях донника лекарственного травы после кислотного гидролиза идентифицировали галловую кислоту и установили ее количественное содержание. Анализ проводили методом ВЭЖХ на хроматографическом модуле «Alliance», оснащенном диодно-матричным детектором и колонкой Wakosil

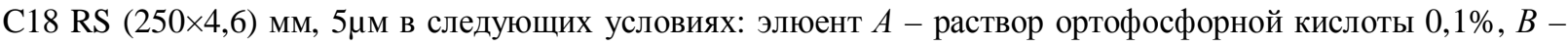
ацетонитрил; градиентный режим; аналитическая длина волны - 275 нм; скорость потока - 1,0 мл/мин; объем инжекции - 10 мкл. 


\section{Обсуждение результатов}

ВРПС донника лекарственного травы представляют собой аморфный порошок серого цвета, при растворении в воде образующий вязкий, опалесцирующий раствор коричневато-серого цвета. Выход ВРПС составил $4,7 \pm 0,5 \%$ в пересчете на абсолютно сухое сырье.

Содержание уроновых кислот в выделенной фракции определяли карбазольным методом. Для диметоксилирования к 5 мл водного раствора ВРПС прибавляли 5 мл раствора натрия гидроксида $0,05 \mathrm{M}$, через 30 мин - 5 мл раствора кислоты хлористоводородной 0,05 М. 0,5 мл полученного раствора помещали в пробирку на ледяную баню, прибавляли 0,5 мл воды и 5 мл раствора натрия тетрабората в серной кислоте. Смесь выдерживали на кипящей водяной бане в течение 6 мин, затем быстро охлаждали и прибавляли 0,2 мл раствора карбазола $0,1 \%$ в абсолютном этиловом спирте. Смесь снова помещали на кипящую водяную баню и выдерживали в течение 10 мин, затем быстро охлаждали. Ярко-красное окрашивание раствора свидетельствовало о наличии уроновых кислот. Измеряли оптическую плотность образовавшегося комплекса на спектрофотометре в максимуме поглощения при длине волны 530 нм. Параллельно в тех же условиях измеряли оптическую плотность раствора галактуроновой кислоты. Содержание уроновых кислот в пересчете на галактуроновую кислоту и абсолютно сухое сырье в траве донника лекарственного составило $0,37 \pm 0,02 \%$.

Для установления моносахаридного состава ВРПС донника лекарственного травы проводили гидролиз ВРПС в среде трифторуксусной кислоты 2 М при температуре кипения в течение 3 ч. В полученном гидролизате методом ВЭЖХ в сравнении с достоверными образцами идентифицировали глюкозу, галактозу, арабинозу, фруктозу, рамнозу и установили их количественное содержание (табл. 1).

В углеводном комплексе, извлекаемом водой из растительного сырья, помимо полисахаридов содержатся моносахара. Их содержание в траве донника лекарственного определяли по следующей методике: 10 г измельченного растительного сырья экстрагировали 50 мл этилового спирта 96\% на водяной бане с обратным холодильником при температуре $70{ }^{\circ} \mathrm{C}$ в течение 30 мин. Экстракцию повторяли дважды в тех же условиях. Объединенное извлечение фильтровали и упаривали на роторном испарителе. Сухой остаток растворяли в 50 мл горячей воды, охлаждали, фильтровали и анализировали методом ВЭЖХ, как указано выше. Содержание в траве донника лекарственного свободной глюкозы составило 3,3\%, фруктозы - 0,6\%.

Для установления аминокислотного состава водного извлечения донника лекарственного травы использовали хроматографические методы. По результатам анализа методом тонкослойной хроматографии проведена предварительная оценка качественного состава аминокислот (табл. 2).

Количественное определение индивидуальных аминокислот проводили методом обращеннофазовой ВЭЖХ с детекцией по светорассеянию. Результаты анализа представлены в таблице 3.

Таблица 1. Результаты анализа моносахаридного состава ВРПС донника лекарственного травы методом ВЭЖХ

\begin{tabular}{c|c|c|c}
\hline \multirow{2}{*}{$№$ пика } & $\begin{array}{c}\text { Время удерживания, } \\
\text { мин. }\end{array}$ & $\begin{array}{c}\text { Стандартный образец, соответствующий } \\
\text { по времени удерживания }\end{array}$ & Содержание, \% \\
\hline 1 & 9,989 & глюкоза & $6,4 \pm 0,5$ \\
2 & 11,008 & галактоза & $15,5 \pm 0,8$ \\
3 & 11,620 & фруктоза & $3,0 \pm 0,4$ \\
4 & 12,164 & арабиноза & $11,4 \pm 0,2$ \\
5 & 12,638 & рамноза & $2,4 \pm 0,2$ \\
\hline
\end{tabular}

Таблица 2. Результаты анализа аминокислотного состава донника лекарственного травы методом ТСХ

\begin{tabular}{c|c|c|c}
\hline № & Значение Rf & Окрашивание & $\begin{array}{c}\text { Стандартный образец, соответствующий по значению } \\
\text { Rf и окрашиванию }\end{array}$ \\
\hline 1 & 0,11 & розовое & Аргинин \\
2 & 0,21 & фиолетовое & Аспарагиновая кислота \\
3 & 0,27 & желтое & - \\
4 & 0,33 & розовое & Глютамин \\
5 & 0,40 & розовое & Треонин \\
6 & 0,56 & розовое & Валин \\
7 & 0,60 & розовое & Изолейцин \\
8 & 0,64 & розовое & Лейцин \\
\hline
\end{tabular}


Таблица 3. Результаты анализа аминокислотного состава донника лекарственного травы методом ВЭЖХ

\begin{tabular}{c|c|c|c}
\hline № пика & Время удерживания, мин & $\begin{array}{c}\text { Стандартный образец, соответствующий } \\
\text { по времени удерживания }\end{array}$ & $\begin{array}{c}\text { Содержание, \% } \\
\text { (в сухом сырье) }\end{array}$ \\
\hline 1 & 3,947 & Аспарагиновая кислота & 0,03 \\
2 & 4,313 & Глютамин & 0,32 \\
3 & 4,518 & Треонин & 0,46 \\
4 & 12,070 & Валин & 0,21 \\
5 & 12,179 & Аргинин & 0,16 \\
6 & 14,442 & Изолейцин & 1,38 \\
7 & 14,741 & лейцин & 0,80 \\
\hline
\end{tabular}

В результате СФМ по нингидриновой реакции общее содержание аминокислот в пересчете на изолейцин и абсолютно сухое сырье в траве донника лекарственного составило $1,6 \pm 0,2 \%$.

Необходимо отметить, что исследуемые водные извлечения получены при длительном кипячении, что исключает наличие в них белка.

Количественное определение фенольных соединений в водном извлечении донника лекарственного травы проводили спектрофотометрическим методом с реактивом Фолина-Чокальтеу. Содержание суммы

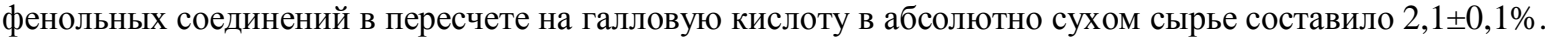

Содержание дубильных веществ (веществ, сорбируемых кожным порошком) в растительном сырье определяли по разности суммы фенольных соединений и фенольных соединений, несорбируемых кожным порошком. Содержание дубильных веществ в пересчете на галловую кислоту в траве донника составило $0,14 \pm 0,02 \%$. По результатам качественных реакций с раствором железоаммониевых квасцов и раствором железа окисного хлорида дубильные вещества донника отнесены к группе гидролизуемых.

В гидролизатах водного извлечения донника травы методом ВЭЖХ установлено наличие галловой кислоты в количестве $0,036 \pm 0,006 \%$ в пересчете на абсолютно сухое сырье, что составляет около $26 \%$ в составе дубильных веществ.

\section{Bblводbl}

1. В результате проведенных исследований установлено, что содержание ВРПС в траве донника лекарственного составляет около 5\%. Физические свойства и компонентный состав ВРПС указывают на присутствие пектиновых веществ. Наличие в составе уроновых кислот составляет около $8 \%$ к полисахаридному комплексу, а основными мономерными звеньями являются арабиноза и галактоза.

2. Суммарное содержание водорастворимых аминокислот составляет 1,6\% в пересчете на изолейцин. Идентифицировано семь свободных аминокислот, четыре из которых являются незаменимыми.

3. Содержание фенольных соединений в растительном сырье составило $2,1 \%$ в пересчете на галловую кислоту и абсолютно сухое сырье.

4. Дубильные вещества донника лекарственного травы являются гидролизуемыми и содержатся в незначительном количестве - 0,14\% в пересчете на галловую кислоту. Содержание галловой кислоты составляет $26 \%$ от суммы дубильных веществ.

\section{Список литературь}

1. Киселева Т.Л., Карпеев А.А. Гомеопатия и фитотерапия в лечении сердечно-сосудистых болезней. М., 1997. $686 \mathrm{c}$.

2. Соколов С.Я. Фитотерапия и фитофармакология: руководство для врачей. М., 2000. 976 с.

3. Блинова К.Ф., Вандышев В.В., Комарова М.Н. Растения для нас: справочное издание. М., 1996. С. $336-338$.

4. Путырский И.Н., Прохоров В.Н. Универсальная энциклопедия лекарственных растений. Минск, 2000. 656 с.

5. ESCOP Monographs. The Scientific Foundation for Herbal Medicinal Prodacts / Second edition. Completely revised and expanded. ESCOP, 2003. $556 \mathrm{c}$.

6. Сычев И.А., Смирнов В.М., Подколзин Г.В. Действие полисахаридов донника желтого на систему кроветворения в норме и при патологии // Российский медико-биологический вестник им. академика И.П. Павлова. 2007. Т. 1, №1. С. 50-58.

7. Сычев И.А., Смирнов В.М., Порядин В.Г. Механизм радиопротекторного действия полисахарида донника желтого - пектина // Вестник РГМУ. 2008. №1. С. 49-54.

8. Турищев С.Н. Современная фитотерапия. М., 2007. 448 с.

9. Дроздова И.Л. Выделение и химическое изучение полисахаридов травы донника рослого (Melilotus altissimus Thuill.) // Вестник ВГУ. Сер.: Химия. Биология. Фармация. 2004. №1. С. 173-175. 
10. Ермаков А.И., Арасимович В.В., Ярош Н.П. Методы биохимического исследования растений. Л., 1987. 430 с.

11. Использование нингидриновой реакции для количественного определения $\alpha$-аминокислот в различных объектах: метод. рекомендации. Волгоград, 2007. 106 с.

12. British Pharmacopoeia. 2009. Vol. IV. A286.

13. Федосеева Л.М. Изучение дубильных веществ подземных и надземных органов бадана толстолистного (Bergenia crassifolia (L.) Fitsch.), произрастающего на Алтае // Химия растительного сырья. 2005. №3. С. 45-50.

Поступило в редакиию 6 марта 2012 2.

После переработки 10 февраля 2013 г.

Fedoseeva L.M. ${ }^{*}$, Harlampovich T.A. ISOLATION AND GENERAL DISCRIPTION OF WATER-SOLUBLE COMPOUNDS OF MELILOTUS OFFICINALIS L.

Altai State Medical University, pr. Lenina, 40, Barnaul, 656038 (Russia), e-mail: ludmila@agmu.ru

The component composition of water-soluble compounds of melilotus officinalis L. was examined was examined with the help by physicochemical method. The quantitative compound of polysaccharides, amino acids, phenolic compounds in water extraction was determined.

The quantitative and qualitative composition of monosaccharides of water-soluble carbohydrate complex and amino acids was determined by HPLC method. The characterization tannins of was given. lic acid.

Keywords: Melilotus officinalis, water-soluble polysaccharides, pectic acid, monosaccharides, amino acids, tannins, gal-

\section{References}

1. Kiseleva T.L., Karpeev A.A. Gomeopatiia i fitoterapiia v lechenii serdechno-sosudistykh boleznei. [Homeopathy and herbal medicine in the treatment of cardiovascular diseases]. Moscow, 1997, 686 p. (in Russ.).

2. Sokolov S.Ia. Fitoterapiia i fitofarmakologiia. Rukovodstvo dlia vrachei. [Phytotherapy and phytopharmacology. Guide for Physicians]. Moscow, 2000, 976 p. (in Russ.).

3. Blinova K.F., Vandyshev V.V., Komarova M.N. Rasteniia dlia nas. Spravochnoe izdanie. [Plants for us. A reference book]. Moscow, 1996, pp. 336-338. (in Russ.).

4. Putyrskii I.N., Prokhorov V.N. Universal'naia entsiklopediia lekarstvennykh rastenii. [Universal Encyclopedia of Medicinal Plants]. Minsk, 2000, 656 p. (in Russ.).

5. ESCOP Monographs. The Scientific Foundation for Herbal Medicinal Prodacts / Second edition. Completely revised and expanded. ESCOP, 2003. $556 \mathrm{c}$.

6. Sychev I.A., Smirnov V.M., Podkolzin G.V. Rossiiskii mediko-biologicheskii vestnik im. akademika I.P. Pavlova, 2007, vol. 1, no. 1, pp. 50-58. (in Russ.).

7. Sychev I.A., Smirnov V.M., Poriadin V.G. Vestnik RGMU, 2008, no. 1, pp. 49-54. (in Russ.).

8. Turishchev S.N. Sovremennaia fitoterapiia. [Sovremennaia fitoterapiia]. Moscow, 2007, 448 p. (in Russ.).

9. Drozdova I.L. Vestnik VGU. Seriia: Khimiia. Biologiia. Farmatsiia, 2004, no. 1, pp. 173-175. (in Russ.).

10. Ermakov A.I., Arasimovich V.V., Iarosh N.P. Metody biokhimicheskogo issledovaniia rastenii. [Methods of Biochemical Plant Research]. Leningrad, 1987, 430 p. (in Russ.).

11. Ispol'zovanie ningidrinovoi reaktsii dlia kolichestvennogo opredeleniia $\alpha$-aminokislot v razlichnykh ob"ektakh: metodicheskie rekomendatsii [Guidelines "Using the ninhydrin reaction for the quantitative determination of $\alpha$-amino acids in different objects."]. Volgograd, 2007, 106 p. (in Russ.).

12. British Pharmacopoeia 2009. Vol. IV. A286.

13. Fedoseeva L.M. Khimiia rastitel'nogo syr'ia, 2005, no. 3, pp. 45-50. (in Russ.).

\footnotetext{
* Corresponding author.
} 
